\title{
Media for Campylobacter jejuni and other campylobacters
}

\author{
D.A.A. Mossel \\ Department of the Science of Food of Animal Origin, The University of Utrecht, P.O. Box 80175, 3508 TD \\ Utrecht, The Netherlands
}

(Received 31 December 1984; accepted 17 February 1985)

\begin{abstract}
Despite their recent elaboration and the many variations in antibiotic combinations designed to attain selectivity, highly selective liquid and solid culture media for Campylobacter jejuni have proved satisfactory provided they are incubated at about $42^{\circ} \mathrm{C}$ and in a microaerophilic atmosphere such as a candle jar. Two reservations apply: (i) cephalothin should not be used when $C$. fetus is to be isolated as well as $C$. jejuni; and (ii) typical colonies obtained on selective isolation media should always be checked for failure to grow on blood agar slants in air.
\end{abstract}

Key words: Campylobacter jejuni; Campylobacter fetus, Candle jar; Cephalothin

\section{Taxonomic essentials}

The examination of foods for Enterobacteriaceae, Staphylococcus aureus, Lancefield group D streptococci, moulds, yeasts, etc. has been carried out for over 50 years and considerable experience has consequently been obtained. On the other hand, definite identification of the genus Campylobacter as an enteric pathogen of man dates back only to about 1970 . Foods have been examined for these organisms for no more than ten years. Nonetheless the procedures adopted from clinical microbiology have been found to work surprisingly well on foods. This does not detract from the fact that here, as in all selective examinations of foods, the Golden Rule applies that the identity of all isolates should be confirmed by verifying the pertinent taxonomic characteristics.

It is generally accepted that of the compylobacters only $C$. jejuni is an enteropathogen transmitted by foods (Butzler, 1984), a situation similar to the yersiniae, where Yersinia enterocolitica seems to be the species of major concern. However, some evidence has been obtained that $C$. fetus may not always be innocuous in the context of foods (Harvey and Greenwood, 1983). It is therefore wise not to overlook the fact that the use of cephalothin, which inhibits $C$. fetus in selective media for campylobacters, may lead to a serious isolation bias. 


\section{Recommended media}

Four combinations of antibiotics have been suggested for inclusion in blood agar to attain a medium that is remarkably selective for campylobacters (Morris et al., 1982). These are the mixtures suggested by Skirrow (Skirrow and Benjamin, 1980), Butzler (Vanhoof et al., 1978; Butzler, 1984), Blaser et al.. 1980 and Wang et al., 1982 and more recently by Butzler's team (Butzler et al., 1983; Goossens et al., 1983). Their composition is given in Table I. There are no essential differences in performance between these combinations and it may be assumed that clinicians will soon reach agreement on the most useful one to the benefit of food microbiologists.

The basal medium need not necessarily be blood agar. Blood-free media, containing reducing ager.ts such as ferrous sulphate and sodium pyruvate, also function quite well (George et al., 1978; Mossel et al., 1983). It is of course essential to incubate media under microaerophilic conditions (Hoffman et al.. 1979) and candle jars serve the purpose well (Luechtefeld et al.. 1982; Mossel et al., 1983).

The minimal infectious dose for $C$. jejuni is low (Robinson, 1981), hence there is a need for enrichment media for this organism. The essential elements of the solid media, a reducing agent and an appropriate combination of antibiotics, will also lead to a successful enrichment medium (Patton et al., 1981; Chan and Mackenzie, 1982; Rothenberg et al., 1984; Hill and Grimes, 1984; Ribeiro and Price, 1984). Incubation at $42^{\circ} \mathrm{C}$ will increase selectivity, although it will not suppress growth of $P s$. aeruginosa, since this is also a thermotrophic bacterium. Therefore it is necessary to verify that typical colonies obtained on isolation media will indeed not be $P S$.

Table I

Antitiotics suggested by various authors for use as selective agents in liquid and solid media for the detection or enumeration of Campylobacter spp. in food or water.

\begin{tabular}{|c|c|c|c|c|c|}
\hline \multicolumn{2}{|l|}{ Antibiotic } & \multirow{2}{*}{\multicolumn{4}{|c|}{$\begin{array}{l}\text { Author's name under which medium } \\
\text { is generally known } \\
\text { (historic order of description) }\end{array}$}} \\
\hline \multirow[t]{2}{*}{ Generic name } & \multirow{2}{*}{$\begin{array}{l}\text { Unit in } \\
\text { which concen- } \\
\text { tration is } \\
\text { expressed }\end{array}$} & & & & \\
\hline & & Skirrow & Butzler & Blaser-Wang & Goossens \\
\hline Amphotericin B & ${\mathrm{mg} 1^{-1}}^{-1}$ & - & - & 2 & 2 \\
\hline Bacitracin & $U 1^{-1}$ & - & 25000 & - & - \\
\hline Cephalothin & $\mathrm{mg} \mathrm{l}^{-1}$ & - & - & 15 & - \\
\hline Cephazolin sodium & $\mathrm{mg}^{-1}$ & - & 15 & - & - \\
\hline Cephoperazon & $\mathrm{mg}^{-1}$ & - & - & - & 15 \\
\hline Colistin sulphate & $\mathrm{U}^{-1}$ & - & 10000 & - & 10000 \\
\hline Cycloheximide & $\mathrm{mg} \mathrm{|}^{-1}$ & - & 50 & - & - \\
\hline Novobiocin & $\mathrm{mg} \mathrm{l}^{-1}$ & - & 5 & - & - \\
\hline Polymyxin B & IU $1^{-1}$ & 2500 & - & 2500 & - \\
\hline Rifampicin & $\mathrm{mg} \mathrm{l}^{-1}$ & - & - & - & 10 \\
\hline Trimethoprim & $\mathrm{mg}^{-1}$ & 5 & - & 5 & - \\
\hline Vancomycin & $\mathrm{mg}^{-1}$ & 10 & - & 10 & - \\
\hline
\end{tabular}


aeroginosa but Campylobacter by sustantiating their failure to grow on blood agar slants incubated aerobically at $37^{\circ} \mathrm{C}$.

It was thought previously that the Campylobacter isolation media in current use would also quantitatively recover sublethally stressed populations. Though this has been substantiated for heat injury (Palumbo, 1984) it has been demonstrated since that this certainly does not apply to cold stress (Ray and Johnson, 1984). Moreover, the use of a non-protective diluent could adversely affect colony counts of stressed cells (Abram and Potter, 1985). Consequently, for the assessment of numbers of colony forming units of Campylobacter species the same precautions must be taken with respect to resuscitation as with the other Gram-negative rod-shaped bacteria of significance in foods (Mossel and van Netten, 1984).

\section{Monitoring procedures}

The procedures used for the monitoring (Mossel, 1982) of liquid and solid selective media for $C$. jejuni are similar to those used for testing Enterobacteriaceae media (cf. Mossel, 1985).

Clearly the test strains are somewhat different and should include (i) four different serotypes of $C$. jejuni and one of C. fetus; (ii) Escherichia coli, Salmonella typhimurium, Staph. aureus, Streptococcus faecalis and Bacillus cereus. Incubation is at $42^{\circ} \mathrm{C}$ under microaerophilic conditions for 24 to $48 \mathrm{~h}$.

The target values indicated for Enterobacteriaceae, both with respect to colony counting, ecometric monitoring and dilution-to-extinction counts (Mossel, 1985), apply also to solid and liquid Campylobacter media.

\section{References}

Abram, D.D. and N.N. Potter, 1985. Diluents and the enumeration of stressed Campylobacter jejuni. J. Food Protect. 48, 135-137.

Blaser, M.J., R.I. Glass, M.I. Huq, B. Stoll, G.M. Kibriya and A.R.M.A. Alim, 1980. Isolation of Campylobacter fetus, subsp. jejuni from Bangladeshi children. J. Clin. Microbiol. 12, 744-747.

Butzler, J.P., M. de Boeck and H. Goossens, 1983. New selective medium for isolation of Campylobacter jejuni from faecal specimens. Lancet I, 818.

Butzler, J.P., 1984. Campylobacter infection in man and animals. CRC Press, Boca Raton, FL, U.S.A.

Chan, F.T.H. and A.M.R. Mackenzie, 1982. Enrichment medium and control system for isolation of Campylobacter fetus subsp. jejuni from stools. J. Clin. Microbiol. 15, 12-15.

George, H.A., P.S. Hoffman, R.M. Smibert and N.R. Krief, 1978. Improved media for growth and aerotolerance of Campylobacter fetus. J. Clin. Microbiol. 8, 26-41.

Goossens, H., M. de Boeck and J.P. Butzler, 1983. A new selective medium for the isolation of Campylobacter jejuni from human faeces. Eur. J. Clin. Microbiol. 2, 389-394.

Harvey, S.M. and J.R. Greenwood, 1983. Probable Campylobacter fetus subsp. fetus gastroenteritis. J. Clin. Microbiol. 18, 1278-1279.

Hill, G.A. and D.J. Grimes, 1984. Seasonal study of a freshwater lake and migratory waterfowl for Campylobacter jejuni. Can. J. Microbiol. 30, 845-849.

Hoffman, P.S., H.A. George, N.R. Krieg and R.M. Smibert, 1979. Studies of the microaerophilic nature of Campylobacter fetus subsp. jejuni. II. Role of exogenous superoxide anions and hydrogen peroxide. Can. J. Microbiol. 25, 8-16. 
Luechtefeld. N.W., L.B. Reller, M.J. Blaser and W.L. Wang, 1982. Comparison of atmospheres of incubation for primary isolation of Campylobacter fetus, subsp. jejuni from animal specimens: $5 \%$ oxygen versus candle jar. J. Clin. Microbiol. 15, 53-57.

Morris, G.K., C.A. Bopp, C.M. Patton and J.G. Wells, 1982. Media for isolating Campylobacter. Arch. Lebensmittelhyg. 33, 151-153.

Mossel, D.A.A., F. van Rossem, M. Koopmans, M. Hendriks, M. Verouden and I. Eelderink. 1980. Quality control of solid culture media. A comparison of the classic and the so-called ecometric technique. J. Appl. Bacteriol. 49, 439-454.

Mossel, D.A.A., 1982. Ecological essentials of the use of selective culture media in public health microbiology. In: Quality assurance and quality control of microbiological culture media, edited by J.E.L. Corry, G.I.T.-Verlag. Darmstadt, pp. 11-19.

Mossel, D.A.A., T.M.G. Bonants-van Laarhoven, A.M.Th. Ligtenberg-Merkus, and M.E.B. Werdler, 1983. Quality assurance of selective culture media for bacteria, moulds and yeasts: An attempt at standardisation at the international level. J. Appl. Bacteriol. 54, 313-327.

Mossel, D.A.A. and P. van Netten, 1984. Harmful effects of selective media on stressed micro-organisms. In: The revival of injured microbes, edited by M.H.E. Andrew and A.D. Russell. Academic Press, London, pp. 329-369.

Mossel, D.A.A., 1985. Media for Enterobacteriaceae. Int. J. Food Microbiol. 2, 27-32.

Palumbo, S.A., 1984. Heat injury and repair in Campylobacter jejuni. Appl. Environm. Microbiol. 48, 477-480.

Patton, C.M., S.W. Mitchell, M.E. Potter and A.F. Kaufman, 1981. Comparison of selective media for primary isolation of Campylobacter fetus subspecies jejuni. J. Clin. Microbiol. 13, 326-330.

Ray, B. and C. Johnson, 1984. Sensitivity of cold-stressed Campylobacter jejuni to solid and liquid selective environments. Food Microbiol. 1, 173-176.

Ribeiro, C.D. and T.H. Price, 1984. The use of Preston enrichment broth for the isolation of 'thermophilic' campylobacters from water. J. Hyg. 92, 45-51.

Robinson, D.A., 1981. Infective dose of Campylobacter jejuni in milk. Br. Med. J. 282, 1584.

Rothenberg, P.J., N.J. Stern and D.C. Westhoff, 1984. Selected enrichment broths for recovery of Campylobacter jejuni from foods. Appl. Environ. Microbiol. 48, 78-80.

Skirrow, M.B. and J. Benjamin, 1980. '1001' Campylobacters: cultural characteristics of intestinal campylobacters from man and animals. J. Hyg. 85, 427-442.

Vanhoof, R., M.P. Vanderlinden, R. Dierickx and J.P. Butzler, 1978. Susceptibility of Campylobacter fetus subsp. jejuni to twenty-nine antimicrobial agents. Antimicrob. Agents Chemother. 14, 553-556.

Wang, W.L., N.W. Luechtefeld, M.J. Blaser and L.B. Reller, 1982. Comparison of CampyPak II with standard 5\% oxygen and candle jars for growth of Campylobacter jejuni from human faeces. J. Clin. Microbiol. 16, 291-294. 